\title{
Age estimation in Brazilian adults by Kvaal's and Cameriere's methods
}

\section{Joyce Campos de MIRANDA(a) Alana de Cássia Silva AZEVEDO(a) Marcos ROCHA(a) iD Edgard MICHEL-CROSATO(a) (D) Maria Gabriela Haye BIAZEVIC(a)}

(a) Universidade de São Paulo - USP, School of Dentistry, Community Dentistry Department, São Paulo, SP, Brazil.

Declaration of Interests: The authors certify that they have no commercial or associative interest that represents a conflict of interest in connection with the manuscript.

\section{Corresponding Author:}

Maria Gabriela Haye Biazevic

E-mail: biazevic@usp.br

https://doi.org/10.1590/1807-3107bor-2020.vol34.0051

Submitted: August 20, 2018

Accepted for publication: March 7, 2020

Last revision: April 30, 2020
Abstract: The aim of this study was to verify the precision and applicability of two methods of age estimation, Kvaal's and Cameriere's methods, among Brazilian adults. A sample composed of periapical radiographs of canine teeth belonging to 320 Brazilian adults was analyzed, divided into groups according to sex (male and female) and age group (20-29 years, 30-39 years, 40-49 years and 50-59 years). Kvaal's method presented better results when compared to the results of Cameriere's method in the general evaluation of each canine tooth, except for the upper left canine (tooth 23), which presented a mean error (ME) with no statistically significant difference between the methods (Kvaal: $\mathrm{ME}=7.43, \mathrm{p}=0.4991$, Cameriere: $\mathrm{ME}=7.55, \mathrm{p}=0.6982$ ). In the evaluation by age groups, Kvaal's method presented a lower variation between the real age and estimated age when applied to the age groups of 20-29 years and 30-39 years compared to the results provided by Cameriere's method. With respect to the groups aged 40 to 49 years and 50 to 59 years, Cameriere's method presented better performance than the results provided by Kvaal's method. The methods of estimating age proposed by Kvaal and Cameriere are simple and nondestructive and have demonstrated reproducibility and reliability. The Kvaal method was more accurate for the age groups of 20-29 and 30-39 years, and for those over 40 years, the Cameriere method was the most accurate.

Keywords: Forensic Sciences; Forensic Dentistry; Age Determination by Skeleton; Cuspid; Radiography, Dental; Adult.

\section{Introduction}

The relevance of the study of age estimation in living individuals is related to its contributions to civil and penal scope before the problems regarding the determination of age in processes of adoption, imputability, pedophilia, absence of valid documents of identification, as well as in situations of migration and asylum application in a foreign country, ${ }^{1,2,3}$ Among adults, in retirement processes, it may also be necessary to calculate the age of the individual.

Several structures of the human body are examined, and various techniques are employed to estimate the age of an individual. Thus, it is possible to estimate the age of the adult dental structure, which undergoes several alterations, including radicular dentine transparency, attrition, modification of the amount of cement rings, racemization of aspartic 
acid, and secondary dentin deposition. ${ }^{4,5}$ The study of secondary dentin deposition is one of the most widely used methods for age estimation in adults, since it is a continuous and regular process modified only by carious lesions or particular abrasions. ${ }^{6}$

The study of the age estimation directed by the deposition of secondary dentin can be performed by sectioning the tooth, by means of radiographs and, recently, volume assessment using cone beam computed tomography (CBCT). The differentiation between primary and secondary dentin is difficult to establish, so an indirect technique is used through the study of the pulp structure. In the case of living individuals, indirect measurements of secondary dentin are performed using radiographs by measurements of length, width and/or area of the tooth and pulp, and correlating them with age. ${ }^{5,7,8}$

When searching for a nondestructible technique to estimate the chronological age of adults, Kvaal et al. ${ }^{9}$ performed the first study based on pulp and tooth measurements using periapical intraoral radiographs. Periapical radiographs of 100 dental patients were selected, and six teeth were selected for the study: upper central incisors, upper and lower lateral incisors, second upper premolars, lower canines and lower first premolars. To compensate for the differences in radiographic enlargement and angulation, the following indices were calculated: the ratios between pulp and root lengths, between pulp and tooth lengths, between tooth and root lengths, and between the pulp length and the root width at three different levels. Regression equations were developed and applied to estimate age. Statistical analysis showed that the Pearson correlation coefficient between age and adopted indices were significant, except for the relation between tooth and root length. The coefficient of determination for the estimation was stronger when all six teeth were included in the analysis $\left(r^{2}=0,76\right)$.

To present a method to estimate the chronological age based on the measurements related to the pulp and tooth area, Cameriere et al. ${ }^{4}$ performed a study with a sample composed of panoramic radiographs of 100 Italian patients, ranging in age from 18 to 72 years. As the only uniradicular tooth present in all radiographs was the right upper canine, and because it had a larger pulp area, this canine was the tooth of choice for the study. Radiographic images were analyzed using the AutoCAD 2000 program. To minimize the distortion and magnification of the radiographic image, the ratio between the pulp area and the canine tooth area was used. The results showed that the variable corresponding to the pulp and tooth area ratio allowed the development of a linear regression equation to calculate the age estimation. The proposed method produced a mean error of less than 4 years; therefore, the authors verified the correlation of the ratio between the pulp area and the tooth area with the chronological age of the individuals.

Estimating age in adults presents many challenges, and the error range of estimations is high, from 8 to 12 years, ${ }^{3,9}$ furthermore, most methods use the different stages of teeth development to perform the estimation, and these techniques lose precision when considering the stability of the adult growth processes. Considering the methods proposed by Kvaal et al. ${ }^{9}$ and Cameriere et al. ${ }^{4}$ for age estimation in adults, this study aimed to evaluate the applicability of these in a sample of Brazilian adults and to verify the precision and applicability of the methods to contribute to the practice of dental experts in Brazil.

\section{Methodology}

The research project was submitted to the Research Ethics Committee of the University of São Paulo and approved (process number 1.608.515).

The sample consisted of 1,280 digital periapical radiographs of healthy canine teeth, belonging to 320 individuals, aged between 20 and 59 years old, divided into groups according to sex (female and male) and age group (20 to 29 years, 30 to 39 years, 40 to 49 years, 50 to 59 years). Each group had 40 research participants. Only the images of individuals who had permanent canine teeth participated in the study. Therefore, individuals with endodontic treatment who used prostheses, used orthodontic appliances, had canines with restorative treatment, had gyroversion, had caries lesions, had tooth attrition, or had supernumerary canines were excluded from the study. 
All radiographic images were collected at the Instituto de Radiologia Papaiz Associados-Diagnósticos por Imagem (São Paulo, Brazil), where radiographic shots were taken using the Timex 70E (Gnatus ${ }$, Barretos, Brazil) X-ray apparatus, set at $70 \mathrm{kVp}-7 \mathrm{~mA}$, with exposure times ranging from 0.6 to $0.8 \mathrm{sec}$, using the indirect digital image capture system.

According to the guidelines presented in the original article of Cameriere et al., ${ }^{4}$, each radiographic image was saved with high resolution in the JPEG file format and imported into the Adobe ${ }^{\circledR}$ Photoshop ${ }^{\circledR}$ CS5 image editing software. Then, the image file was opened and expanded. If necessary, the adjustment of brightness, contrast and sharpness was performed. From the toolbar of the program, the polygonal loop tool was selected with the aim of using it to demarcate the contour of the entire canine tooth and its pulp structure. To perform the contour of the structures, it was necessary to click on a starting point that bordered the tooth to begin the definition of all the points that interconnect by means of a line, which resulted in the outline of the contour of the tooth. Second, the same was done to contour the pulp. A minimum of 20 points was identified to contour the entire canine, and a minimum of 10 points was marked in the contour of the pulp. To be aware of the number of pixels pertaining to the tooth contour layer and the pulp contour layer, the histogram palette was activated, and through it, the RGB channel and the "selected layer" option were selected. In this way, the histogram displayed the number of pixels for each of the selected layers. By observing the "CONTOURPULP" layer, the pixel value of the pulp structure was obtained, and by selecting the "CONTOUR-TOOTH" layer, the number of pixels contained in each canine tooth was visualized.

The ages were estimated through the application of the equations proposed by Cameriere et al. ${ }^{4}$ : one for upper canines (a) and one for lower canines (b). In these equations, the values in pixels of the tooth and the pulp were required to estimate the age.

(a) Upper Canine:

Age $=99.937-532.775 \times$ (Pixels of the pulp / pixels of the upper canine); (b) Lower Canine:

Age $=89.456$

For the method of Kvaal et al., ${ }^{9}$ the measurements were also performed in Adobe ${ }^{\circledR}$ Photoshop ${ }^{\circledR}$ CS5 software. All canine teeth were evaluated, and linear measurements were obtained. The tooth length $(\mathrm{T})$, pulp length $(\mathrm{P})$, root length $(\mathrm{R})$ and root and pulp widths were evaluated at three different levels: at the cement-enamel junction (level A), at $1 / 4$ of the root length from the cement-enamel junction (level B), and between the cement-enamel junction and the root apex (level C). The values obtained were applied in the following equation to age estimation:

Age $=158.8-255.7 \times \mathrm{M}$; being $\mathrm{M}=\frac{P+R+A+B+C}{5}$

Before beginning the analysis of the radiographs of the study, the examiners underwent a period of learning about the technique and improving it. An interexaminer analysis was performed (comparison with the gold standard) so that $10 \%$ of the radiographs that were part of this study were evaluated by calibrated examiners independently. In analyzing the radiographic images, the observers had no prior knowledge of the subject's chronological age. The intraclass correlation coefficient (ICC) was used in this regard.

In the data analysis, the descriptive statisticsmean and standard deviation-were used to describe the differences between real age (IR) and estimated age (IE). Student's t test was also used to compare the real versus estimated ages of the methods studied in this article at a $5 \%$ level of significance. The data were entered into spreadsheets in Excel, and the statistical calculations were performed using STATA 13.0.

\section{Results}

To evaluate the reproducibility of the methods of age estimation, intraexaminer and interexaminer agreement (for comparison with the gold standard) tests were performed, and the results indicate that Cameriere's method (ICC $=0.852$; $\mathrm{ICC}=0.786$ ) presented higher agreement values than those of 
Kvaal's method $(\mathrm{ICC}=0.711 ;$ ICC $=0.674)$ (Table 1 and Figure 1). Figure 1 shows the mean differences between observers 1 and 2 in Kvaal's (A, mean = 1.5)

Table 1. Results regarding intra-examiner and inter-examiner agreement for the age estimation methods applied in the study.

\begin{tabular}{llll}
\hline Examiner & $\mathrm{CCl}$ & Min & Max \\
\hline Kvaal et al. ${ }^{9}$ & & & \\
Intra-examiner & 0.711 & 0.578 & 0.834 \\
Inter-examiner & 0.674 & 0.483 & 0.771 \\
$\begin{array}{l}\text { Cameriere et al. }{ }^{4} \\
\text { Intra-examiner }\end{array}$ & 0.852 & 0.689 & 0.934 \\
Inter-examiner & 0.786 & 0.597 & 0.898 \\
\hline ICC: & & \\
\end{tabular}

ICC: intraclass correlation coefficient; Min :minimum; Max: maximum.
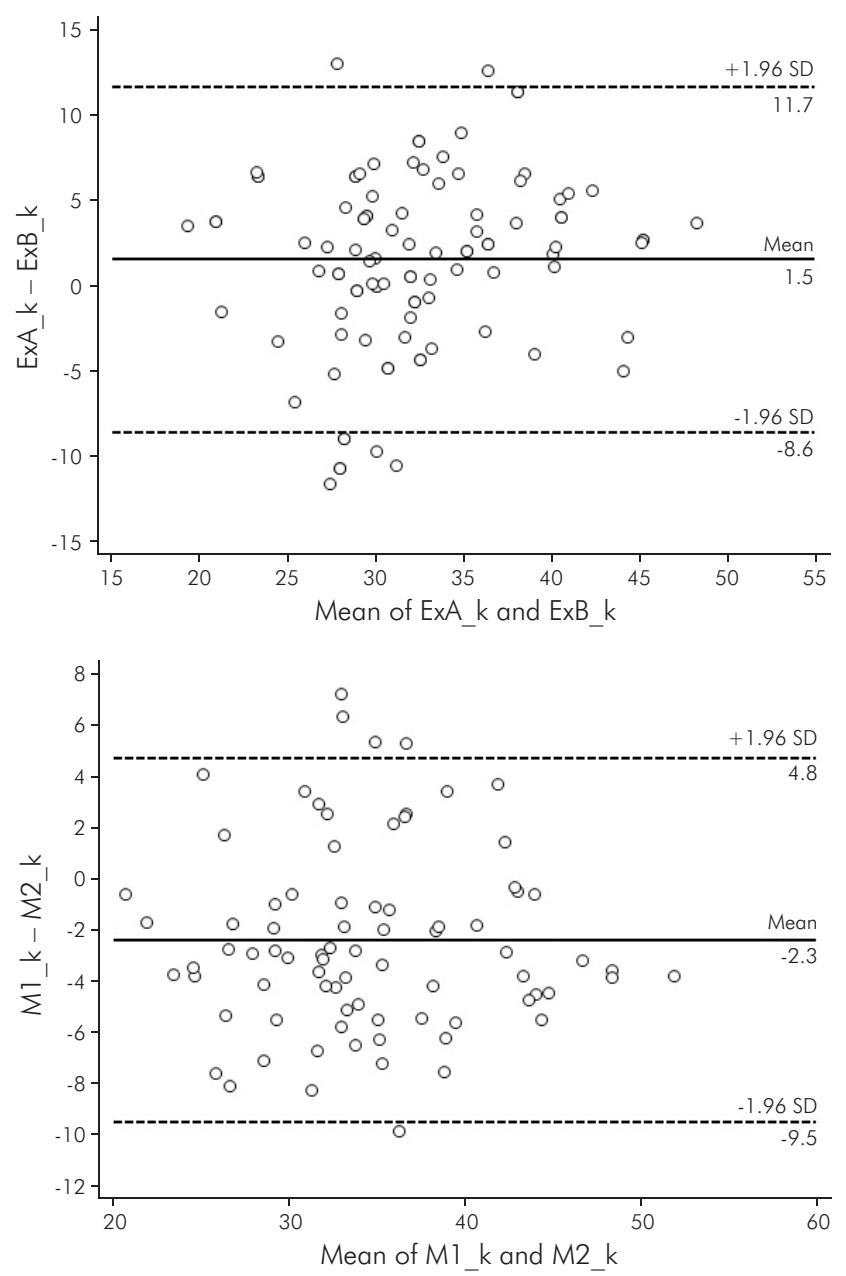

and Cameriere's $(B$, mean $=1.0)$ techniques; also, the same figure shows intraobserver agreement using Kvaal's $(C$, mean $=-2.3)$ and Cameriere's $(\mathrm{D}$, mean $=1.0)$ methods.

Figure 2 shows the agreement between Kavaal's and Cameriere's methods; Cameriere's method estimated the mean ages approximately 5 more years than the ages estimated by Kvaal's method, and some points were outside the confidence interval.

When the mean age was estimated for each age group, a better performance of Kvaal's method was observed for the younger age groups (20 to 29 years, 30 to 39 years). For the age groups between 40 and 49 years and 50 to 59 years, Cameriere's technique presented better results (Table 2).
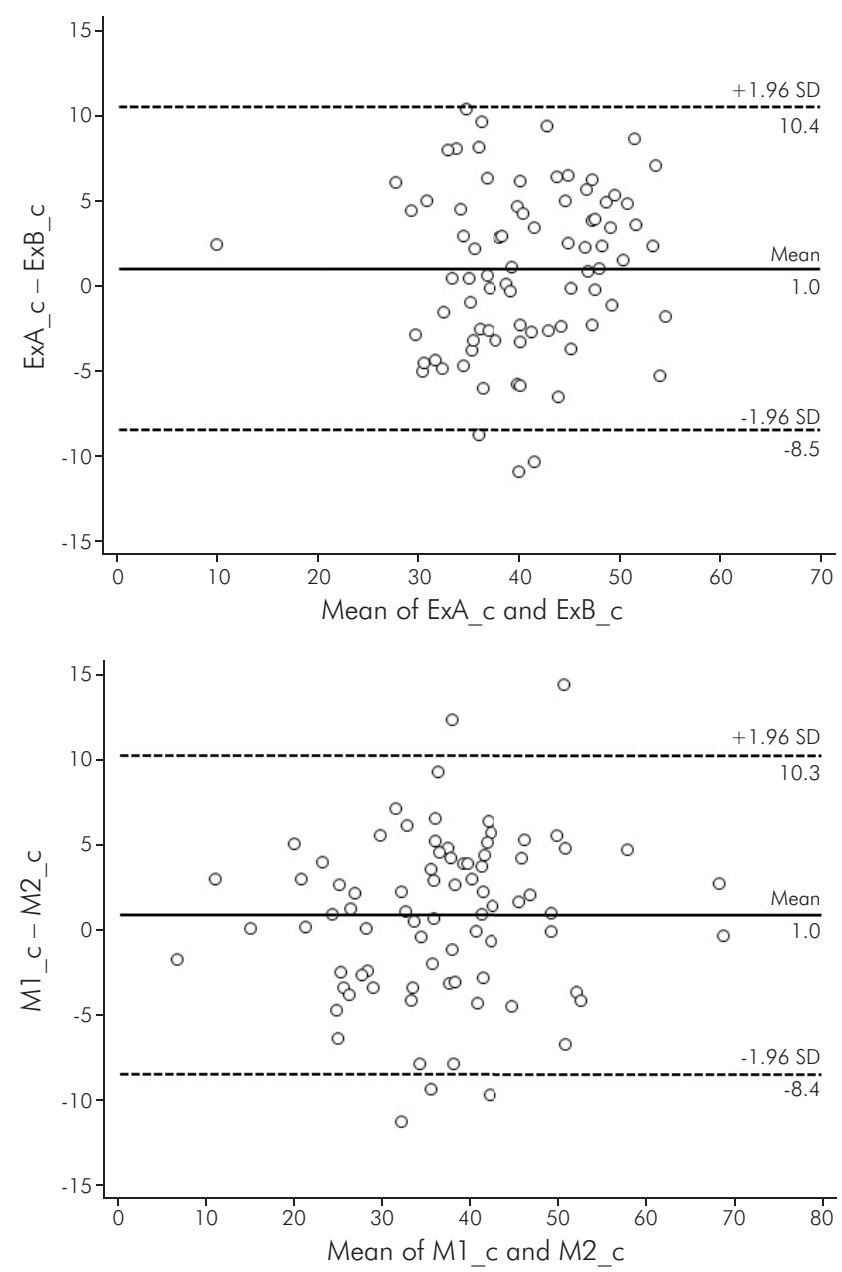

Figure 1. Bland Altman agreement analysis. Mean differences between both observers in Kvaal's (A) and Cameriere's (B) techniques; intra-observer agreement using Kvaal's (C) and Cameriere's (D) methods. 


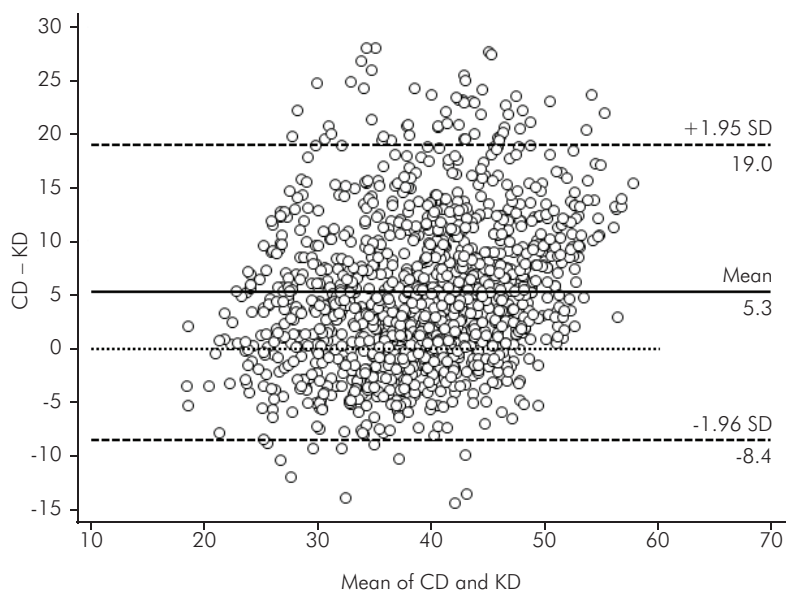

Figure 2. Bland Altman agreement analysis. Mean differences between both methods, Kvaal (K) and Cameriere (C).

Regarding the mean error of the methods studied and the age groups (Table 3), it was observed that for the 20- to 29-year-old age group, the smallest error was obtained when studying the right upper canine (real age, $\mathrm{RA}=25.74 ; \mathrm{SD}=2.60$; mean error, $\mathrm{ME}=4.63 ; \mathrm{SD}=3.39$ ) with Kvaal's technique. ${ }^{9}$ In the group of individuals aged between 30 and 39 years, the lower left canine presented better performance for Kvaal's method ${ }^{9}$ with RA $=34.09(\mathrm{SD}=2.62)$ and $\mathrm{ME}=5.42$ years $(\mathrm{SD}=3.51)$. In the age group of 40 to 49 years, the best result was obtained by Cameriere's method $^{4}$ when evaluating the lower left canine $(\mathrm{RA}=43.63 ; \mathrm{SD}=2.62 ; \mathrm{ME}=6.71 ; \mathrm{SD}=4.63)$. For individuals over 50 years of age, the lowest mean error value was found when applying Cameriere's method $^{4}$ in the right lower canine $(\mathrm{RA}=53.94$; $\mathrm{SD}=$ 2.72; $\mathrm{ME}=6.73 ; \mathrm{SD}=5.95$ ).

Kvaal's method ${ }^{9}$ showed better results when compared to those of Cameriere's method ${ }^{4}$ in the general evaluation for each of the canine teeth, except for the upper left canine (tooth 23), which presented a mean error with no statistically significant difference between the methods (Kvaal: $\mathrm{ME}=7.43 ; \mathrm{p}=0.3491$; Cameriere: $\mathrm{ME}=7.55 ; \mathrm{p}=0.6982$ ). The lowest mean error for Kvaal's method was obtained for the lower left canine (ME=6.81; $\mathrm{SD}=4.06)$; for Cameriere's method, the tooth that presented the best result was the upper left canine $(\mathrm{ME}=7.55 ; \mathrm{SD}=5.35)($ Table 4$)$.
Table 2. Mean of real ages and estimated ages by the Kvaal et al. ${ }^{9}$ and Cameriere et al. ${ }^{4}$ methods by age groups.

\begin{tabular}{|c|c|c|c|c|c|}
\hline Variables & $\mathrm{n}$ & Mean & SD & Min & Max \\
\hline \multicolumn{6}{|c|}{20 to 29 years - Kvaal et al. ${ }^{9}$} \\
\hline Real age & 80 & 25.74 & 2.60 & 20.42 & 29.92 \\
\hline Tooth 13 & 80 & 28.35 & 5.21 & 20.54 & 39.34 \\
\hline Tooth 23 & 80 & 27.62 & 6.08 & 17.09 & 40.79 \\
\hline Tooth 33 & 80 & 29.23 & 5.66 & 20.27 & 41.18 \\
\hline Tooth 43 & 80 & 29.77 & 5.60 & 19.94 & 43.87 \\
\hline \multicolumn{6}{|c|}{20 to 29 years - Cameriere et al. ${ }^{4}$} \\
\hline Real age & 80 & 25.74 & 2.60 & 20.42 & 29.92 \\
\hline Tooth 13 & 80 & 35.31 & 6.36 & 15.92 & 49.11 \\
\hline Tooth 23 & 80 & 34.64 & 7.02 & 19.64 & 52.76 \\
\hline Tooth 33 & 80 & 35.95 & 8.83 & 17.44 & 54.29 \\
\hline Tooth 43 & 80 & 36.05 & 9.00 & 21.07 & 56.46 \\
\hline \multicolumn{6}{|c|}{30 to 39 years - Kvaal et al. ${ }^{9}$} \\
\hline Real age & 80 & 34.09 & 2.62 & 30 & 39.5 \\
\hline Tooth 13 & 80 & 36.38 & 6.33 & 20.21 & 47.29 \\
\hline Tooth 23 & 80 & 37.54 & 6.27 & 24.89 & 49.8 \\
\hline Tooth33 & 80 & 37.41 & 5.49 & 20.05 & 49.41 \\
\hline Tooth43 & 80 & 36.82 & 5.72 & 20.15 & 51.53 \\
\hline \multicolumn{6}{|c|}{30 a 39 years - Cameriere et al. ${ }^{4}$} \\
\hline Real age & 80 & 34.09 & 2.62 & 30 & 39.5 \\
\hline Tooth 13 & 80 & 40.12 & 7.24 & 25.59 & 54.3 \\
\hline Tooth23 & 80 & 39.15 & 7.03 & 24.85 & 54.54 \\
\hline Tooth33 & 80 & 39.05 & 7.20 & 22.88 & 55.1 \\
\hline Tooth43 & 80 & 39.24 & 7.72 & 16.72 & 57.69 \\
\hline \multicolumn{6}{|c|}{40 a 49 years - Kvaal et al. ${ }^{9}$} \\
\hline Real age & 80 & 43.63 & 2.62 & 40 & 49.67 \\
\hline Tooth 13 & 80 & 36.18 & 4.00 & 28.75 & 45.07 \\
\hline Tooth23 & 80 & 36.12 & 3.28 & 28.92 & 46.44 \\
\hline Tooth33 & 80 & 36.54 & 3.47 & 30.17 & 44.15 \\
\hline Tooth43 & 80 & 36.48 & 3.74 & 26.8 & 47.55 \\
\hline \multicolumn{6}{|c|}{40 a 49 years - Cameriere et al. ${ }^{4}$} \\
\hline Real age & 80 & 43.63 & 2.62 & 40 & 49.67 \\
\hline Tooth 13 & 80 & 43.38 & 7.82 & 26.39 & 62.01 \\
\hline Tooth23 & 80 & 42.76 & 7.00 & 27.13 & 59.09 \\
\hline Tooth33 & 80 & 44.83 & 7.97 & 27.31 & 59.32 \\
\hline Tooth43 & 80 & 44.37 & 7.38 & 27.54 & 58.11 \\
\hline \multicolumn{6}{|c|}{50 a 59 years - Kvaal et al. ${ }^{9}$} \\
\hline Real age & 80 & 53.94 & 2.72 & 50 & 59.92 \\
\hline Tooth 13 & 80 & 43.33 & 4.22 & 30.15 & 51.96 \\
\hline Tooth23 & 80 & 43.20 & 4.39 & 30.29 & 51.02 \\
\hline Tooth33 & 80 & 44.38 & 3.33 & 35.96 & 51.01 \\
\hline Tooth43 & 80 & 44.90 & 3.67 & 31.58 & 54.82 \\
\hline \multicolumn{6}{|c|}{50 a 59 years - Cameriere et al. ${ }^{4}$} \\
\hline Real age & 80 & 53.94 & 2.72 & 50 & 59.92 \\
\hline Tooth 13 & 80 & 48.02 & 7.48 & 27.83 & 65.45 \\
\hline Tooth23 & 80 & 47.34 & 6.80 & 26.68 & 63.48 \\
\hline Tooth33 & 80 & 49.48 & 7.82 & 30.54 & 65.91 \\
\hline Tooth43 & 80 & 49.33 & 7.77 & 26.59 & 66.21 \\
\hline
\end{tabular}

SD: standard deviation; Min: minimum, Max: maximum. 
Table 3. Mean error between real age and estimated age by the Kvaal et al. ${ }^{9}$ and Cameriere et al. ${ }^{4}$ methods by age groups.

\begin{tabular}{|c|c|c|c|c|c|c|}
\hline Variables & $n$ & $\begin{array}{l}\text { Mean } \\
\text { Error }\end{array}$ & SD & Min & Max & $\mathrm{p}$-value \\
\hline \multicolumn{7}{|c|}{20 to 29 years - Kvaal et al. ${ }^{9}$} \\
\hline Tooth 13 & 80 & 4.63 & 3.39 & 0.02 & 16.51 & $<0.001$ \\
\hline Tooth 23 & 80 & 5.23 & 3.72 & 0.1 & 14.54 & $<0.001$ \\
\hline Tooth 33 & 80 & 5.06 & 3.86 & 0.38 & 17.51 & $<0.001$ \\
\hline Tooth 43 & 80 & 5.49 & 3.63 & 0.06 & 15.12 & $<0.001$ \\
\hline \multicolumn{7}{|c|}{20 to 29 years - Cameriere et al. ${ }^{4}$} \\
\hline Tooth 13 & 80 & 9.85 & 5.55 & 0.92 & 23.06 & $<0.001$ \\
\hline Tooth 23 & 80 & 9.35 & 5.85 & 0.01 & 23.94 & $<0.001$ \\
\hline Tooth 33 & 80 & 10.18 & 6.89 & 0.02 & 29.62 & $<0.001$ \\
\hline Tooth 43 & 80 & 10.64 & 7.68 & 0.03 & 29.63 & $<0.001$ \\
\hline \multicolumn{7}{|c|}{30 to 39 years - Kvaal et al. ${ }^{9}$} \\
\hline Tooth 13 & 80 & 6.1 & 3.18 & 0.22 & 14.01 & $<0.001$ \\
\hline Tooth 23 & 80 & 6.18 & 3.93 & 0.02 & 17.3 & 0.0249 \\
\hline Tooth 33 & 80 & 5.42 & 3.51 & 0.13 & 15.58 & 0.0003 \\
\hline Tooth 43 & 80 & 5.77 & 3.21 & 0.25 & 15.8 & 0.0001 \\
\hline \multicolumn{7}{|c|}{30 to 39 years - Cameriere et al. ${ }^{4}$} \\
\hline Tooth 13 & 80 & 8.16 & 4.78 & 0.15 & 19.73 & $<0.001$ \\
\hline Tooth 23 & 80 & 7.14 & 5.06 & 0.58 & 22.04 & 0.0497 \\
\hline Tooth 33 & 80 & 7.03 & 5.1 & 0.03 & 21.6 & 0.0006 \\
\hline Tooth 43 & 80 & 7.63 & 5.1 & 0.24 & 22.52 & 0.0003 \\
\hline \multicolumn{7}{|c|}{40 to 49 years - Kvaal et al. ${ }^{9}$} \\
\hline Tooth 13 & 80 & 7,64 & 3.51 & 1.92 & 19.32 & 0.9791 \\
\hline Tooth 23 & 80 & 7.56 & 3.34 & 0.52 & 20.74 & 0.9975 \\
\hline Tooth 33 & 80 & 7.22 & 3.81 & 0.02 & 15.48 & 0.7778 \\
\hline Tooth 43 & 80 & 7.44 & 3.49 & 0.52 & 20.12 & 0.9586 \\
\hline \multicolumn{7}{|c|}{40 to 49 years - Cameriere et al. ${ }^{4}$} \\
\hline Tooth 13 & 80 & 6.47 & 4.92 & 0.16 & 20.52 & 0.0417 \\
\hline Tooth 23 & 80 & 6.08 & 4.19 & 0.26 & 19.79 & 0.0051 \\
\hline Tooth 33 & 80 & 6.71 & 4.63 & 0.2 & 19.61 & 0.4444 \\
\hline Tooth 43 & 80 & 6.36 & 4.44 & 0.03 & 17.04 & 0.0828 \\
\hline \multicolumn{7}{|c|}{50 to 59 years - Kvaal et al. ${ }^{9}$} \\
\hline Tooth 13 & 80 & 10.61 & 4.22 & 2.72 & 23.65 & 1.000 \\
\hline Tooth 23 & 80 & 10.74 & 4.47 & 1.4 & 22.46 & 1.000 \\
\hline Tooth 33 & 80 & 9.55 & 3.46 & 0.06 & 18.79 & 1.000 \\
\hline Tooth 43 & 80 & 9.12 & 3.65 & 0.21 & 22.17 & 1.000 \\
\hline \multicolumn{7}{|c|}{50 to 59 years - Cameriere et al. ${ }^{4}$} \\
\hline Tooth 13 & 80 & 7.79 & 5.36 & 0.15 & 23.92 & $<0.001$ \\
\hline Tooth 23 & 80 & 7.64 & 5.69 & 0.04 & 26.07 & $<0.001$ \\
\hline Tooth 33 & 80 & 6.99 & 5.49 & 0.11 & 23.21 & $<0.001$ \\
\hline Tooth 43 & 80 & 6.73 & 5.95 & 0.2 & 27.16 & 0.0001 \\
\hline
\end{tabular}

SD: standard deviation; Min: minimum, Max: maximum.
Table 5 shows the comparison results between the real age and estimated age as per sex and technique, and the $p$ values show whether these comparisons are significant. The age estimation obtained from the analysis of the right upper canine (tooth 13) presented better results for females (Kvaal: $\mathrm{ME}=6.95$; Cameriere: $\mathrm{ME}=7.70$ ) when compared to males (Kvaal: ME=7.54; Cameriere: $\mathrm{ME}=8.43$ ). For tooth 13, method errors were close to the limit of statistical significance ( $p$ value 0.05 ) in both sexes. (Table 5).

In relation to the upper left canine (tooth 23), the female sex presented an ME of 7.24 years for Kvaal's method and an ME of 6.57 years for Cameriere's method; on the other hand, the male sex showed an ME of 7.61 years for Kvaal's method and an ME of 8.53 years for Cameriere's method (Table 5). Among females, there was no statistically significant difference between the estimation methods used in the study.

For the lower left canine (tooth 33), the female sex (Kvaal: $\mathrm{ME}=6.26$; Cameriere: $\mathrm{ME}=6.93$ ) also presented lower mean error values when compared to those of the male sex (Kvaal: $\mathrm{ME}=7.36$; Cameriere: $M E=9.03)$. There was no significant difference between the methods for the female sex; however, for the male sex, Kvaal's method was statistically superior to Cameriere's method (Table 5).

In reference to the right lower canine (tooth 43), the best results of estimated ages were observed for women (Kvaal: $\mathrm{ME}=6.52$; Cameriere: $\mathrm{ME}=6.73$ ) when compared to the results observed for men. Kvaal's method was the best for the male sex (Table 5).

\section{Discussion}

Although the scientific literature has presented different techniques for age estimation by means of the study of teeth, many present a high degree of complexity or advocate the destruction of dental tissues and, therefore, are not applicable for living individuals. The best option for age estimation in vivo is through the indirect evaluation of dental structure by means of a simple, nondestructive radiographic examination that generates images of clinically invisible structures. ${ }^{10,11,12,13}$ 
Table 4. Mean error of ages estimated by the Kvaal et al. ${ }^{9}$ and Cameriere et al. ${ }^{4}$ methods according to the dental unit studied.

\begin{tabular}{|c|c|c|c|c|c|c|}
\hline Methods & $n$ & Mean (error) & Standard deviation & \multicolumn{2}{|c|}{ Confidence interval (95\%) } & $\mathrm{p}$-value \\
\hline \multicolumn{7}{|l|}{ Tooth 13} \\
\hline Kvaal & 320 & 7.24 & 4.21 & 6.78 & 7.71 & 0.0049 \\
\hline Cameriere & 320 & 8.07 & 5.28 & 7.49 & 8.65 & 0.0098 \\
\hline \multicolumn{7}{|l|}{ Tooth 23} \\
\hline Kvaal & 320 & 7.43 & 4.39 & 6.94 & 7.91 & 0.3491 \\
\hline Cameriere & 320 & 7.55 & 5.35 & 6.96 & 8.14 & 0.6982 \\
\hline \multicolumn{7}{|l|}{ Tooth 33} \\
\hline Kvaal & 320 & 6.81 & 4.06 & 6.36 & 7.26 & 0.0005 \\
\hline Cameriere & 320 & 7.98 & 5.86 & 7.33 & 8.62 & 0.0010 \\
\hline \multicolumn{7}{|l|}{ Tooth 43} \\
\hline Kvaal & 320 & 6.95 & 3.78 & 6.54 & 7.37 & 0.0058 \\
\hline Cameriere & 320 & 7.84 & 6.13 & 7.17 & 8.52 & 0.0115 \\
\hline
\end{tabular}

Table 5. Comparison of the results obtained for the Kvaal and Cameriere methods as per sex.

\begin{tabular}{|c|c|c|c|c|c|c|}
\hline Methods & $\mathrm{n}$ & Mean (error) & $\begin{array}{l}\text { Standard } \\
\text { deviation }\end{array}$ & $\begin{array}{c}\text { Confidence } \\
\text { interval (95\%) }\end{array}$ & $\mathrm{p}$-value & $\mathrm{p}$-value \\
\hline \multicolumn{7}{|c|}{ Tooth 13 - Male } \\
\hline Kvaal & 160 & 7.54 & 3.83 & 6.94 & 8.14 & 0.0288 \\
\hline Cameriere & 160 & 8.43 & 5.43 & 5.43 & 7.58 & 0.0575 \\
\hline \multicolumn{7}{|c|}{ Tooth 13 - Female } \\
\hline Kvaal & 160 & 6.95 & 4.55 & 6.24 & 7.66 & 0.0466 \\
\hline Cameriere & 160 & 7.70 & 5.12 & 6.90 & 8.50 & 0.0812 \\
\hline \multicolumn{7}{|c|}{ Tooth 23 - Male } \\
\hline Kvaal & 160 & 7.61 & 4.17 & 6.96 & 8.26 & 0.0232 \\
\hline Cameriere & 160 & 8.53 & 5.37 & 7.69 & 9.37 & 0.0444 \\
\hline \multicolumn{7}{|c|}{ Tooth 23 - Female } \\
\hline Kvaal & 160 & 7.24 & 4.62 & 6.52 & 7.96 & 0.9330 \\
\hline Cameriere & 160 & 6.57 & 5.16 & 5.76 & 7.38 & 0.1339 \\
\hline \multicolumn{7}{|c|}{ Tooth 33 - Male } \\
\hline Kvaal & 160 & 7.36 & 3.83 & 6.76 & 7.96 & 0.0006 \\
\hline Cameriere & 160 & 9.03 & 6.04 & 8.09 & 9.98 & 0.0012 \\
\hline \multicolumn{7}{|c|}{ Tooth 33 - Female } \\
\hline Kvaal & 160 & 6.26 & 4.21 & 5.60 & 6.92 & 0.0845 \\
\hline Cameriere & 160 & 6.93 & 5.50 & 6.07 & 7.78 & 0.1690 \\
\hline \multicolumn{7}{|c|}{ Tooth 43 - Male } \\
\hline Kvaal & 160 & 7.39 & 3.40 & 6.86 & 7.92 & 0.0017 \\
\hline Cameriere & 160 & 8.95 & 6.61 & 7.92 & 9.98 & 0.0034 \\
\hline \multicolumn{7}{|c|}{ Tooth 43 - Female } \\
\hline Kvaal & 160 & 6.52 & 4.08 & 5.88 & 7.16 & 0.3213 \\
\hline Cameriere & 160 & 6.73 & 5.40 & 5.89 & 7.58 & 0.6426 \\
\hline
\end{tabular}


When carrying out the linear measurements proposed by Kvaal. et al. ${ }^{9}$ and the area measurements established by Cameriere et al., ${ }^{4}$ in the periapical radiographs, the intraclass correlation coefficient for concordance evaluation showed that the methods generated reproducible and reliable measurements, which corroborated the results of other studies. ${ }^{23,6,7,7,14}$ Two observers performed the measurements for training purposes (comparison with the gold standard), but all analyses were performed by one of them. In this context, data of interobserver agreement demonstrated that both techniques were reproducible after proper training.

The analyzed sample was obtained using digital radiology, and some authors ${ }^{7,11,15}$ state that despite the quality of the digital radiographs, there are difficulties in identifying the points of reference for the realization of the measurements, whether they were linear or for the demarcation of the area in pixels. The conditions of visualization (monitor, resolution, image quality, external light) and human limitations can influence the quality of the measurements obtained in the techniques of age estimation.

In this study, the mean error for Cameriere's technique, when evaluating each canine tooth separately, ranged from 7.55 years $(\mathrm{SD}=5.35)$ to 8.07 years $(S D=5.28)$. Similar results were observed in the study by Azevedo et al., ${ }^{3}$ in which the mean error ranged from 7.99 years $(\mathrm{SD}=6.78)$ to 8.56 years $(\mathrm{SD}=5.80)$. In the work published by Cameriere et al. ${ }^{16}$, the mean error was lower, ranging from 2.37 years for upper canines to 2.55 years for lower canines. However, it should be noted that in this publication of 2009, the teeth studied came from an osteological collection, a fact that facilitates the acquisition of radiographic images and the analysis of images without overlapping adjacent structures. Other factors may have influenced the results, as follows: exposure technique, patients' and X-ray film positioning during the image caption, individual variability of the dental morphology and secondary dentin deposit over time.

Kvaal's method, when evaluating the lower left canine, presented the lowest mean error with a value of 6.81 years $(\mathrm{SD}=4.06)$, and the largest error of this method was obtained for the left upper canine with an equal error to 7.43 years $(\mathrm{SD}=4.39)$. In the original study by Kvaal et al., the mean error for the canine tooth was 11.5 years. Paewinsky et al. ${ }^{17}$ applied Kvaal's method on panoramic radiographs and found a difference between real ages and estimated ages ranging from 6.61 to 10.02 years. In a study with the Belgian population, Kvaal's method presented a mean error of 8.1 to 11.6 years. ${ }^{18}$ However, Landa et al. ${ }^{14}$ studied Kvaal's method in Spanish and detected a marked underestimation, with errors between real ages and estimated ages varying from 12.53 to 14.95 years. Additionally, another study found low accuracy using the same method on cone beam computer tomography data ${ }^{12}$ with a variation of more than 10 years.

Schmeling et al. ${ }^{19}$ classified the morphological and radiographic characteristics of the teeth of adult individuals as moderate and stated that the error of the estimated ages in several studies ranged between 6 and 8 years of age.

The results with no discrimination regarding sex and age group are presented (Table 4), since it is possible that this information is not available in real cases. Since our initial hypothesis was that there could be differences among males and females, we added the results with respect to sex and verified that the mean error of the age estimations was similar in this regard.

The findings related to the analysis of each of the four canine teeth demonstrated that Kvaal's method was superior to Cameriere's method, except for the results for the upper left canine, which did not present a significant difference. In the evaluation by homogeneous age groups, the findings allow us to state that Kvaal's method presented better results when applied to the younger adult age groups (20-29 years, 30-39 years). With respect to the groups aged 40 to 49 years and 50 to 59 years, Cameriere's method presented better performance. For Azevedo et al.", the lowest variation was also found in the group of 40 to 49 years (ME $=6.08$ 6.87 years; $\mathrm{SD}=4.04-4.83$ ). Regarding sex, women presented better results for the estimated ages when compared to those of men for both methods. We performed a comparison of two methods for dental age estimation in adults to verify whether 
it was possible to narrow the error range of the estimations, but many studies have found similar results for dental age estimation in adults, which is a topic that forensic dentistry must work on in the future.

Although radiographic evaluation of dentin-pulpal complex modifications from the secondary dentin deposit did not show maximum precision (estimated age equal to actual age) in the age estimation of living adults, it is still the best nondestructible parameter available ${ }^{5}$. Furthermore, it was not expected to reach the real age, since it is only possible to estimate age with these methods. This limitation of this study is not having a specific range for dental age estimation among Brazilian adults, since it is known that the older the individual is, the more challenging it is to perform a precise age estimation.

In conclusion, the methods of age estimation proposed by Kvaal et al. ${ }^{9}$ and Cameriere et al. ${ }^{4}$ are simple, noninvasive, and can be applied among Brazilians. Kvaal's method was more accurate for the groups aged 20 to 29 and 30 to 39 years, and over 40 years of age, Cameriere's method was the most accurate.

\section{Acknowledgments}

The investigators would like to acknowledge the State of São Paulo's Research Fund (FAPESP, process number 2016/07508-8) which provided the funding to perform this investigation.

\section{References}

1. Cunha E, Baccino E, Martrille L, Ramsthaler F, Prieto J, Schuliar Y, et al. The problem of aging human remains and living individuals: a review. Forensic Sci Int. 2009 Dec;193(1-3):1-13. https://doi.org/10.1016/j.forsciint.2009.09.008

2. Karkhanis S, Mack P, Franklin D. Age estimation standards for a Western Australian population using the dental age estimation technique developed by Kvaal et al. Forensic Sci Int. 2014 Feb;235:104.e1-6. https://doi.org/10.1016/i.forsciint.2013.12.008

3. Azevedo AC, Alves NZ, Michel-Crosato E, Rocha M, Cameriere R, Biazevic MG. Dental age estimation in a Brazilian adult population using Cameriere's method. Braz Oral Res. 2015;29(1):1-9. https://doi.org/10.1590/1807-3107BOR-2015.vol29.0016

4. Cameriere R, Ferrante L, Cingolani M. Variations in pulp/tooth area ratio as an indicator of age: a preliminary study. J Forensic Sci. 2004 Mar;49(2):317-9. https://doi.org/10.1520/JFS2003259

5. Babshet M, Acharya AB, Naikmasur VG. Age estimation in Indians from pulp/tooth area ratio of mandibular canines. Forensic Sci Int. 2010 Apr;197(1-3):125.el-4. https://doi.org/10.1016/j.forsciint.2009.12.065

6. Cameriere R, Ferrante L, Belcastro MG, Bonfiglioli B, Rastelli E, Cingolani M. Age estimation by pulp/tooth ratio in canines by peri-apical X-rays. J Forensic Sci. 2007 Jan;52(1):166-70. https://doi.org/10.1111/j.1556-4029.2006.00336.x

7. Erbudak HÖ, Ozbek M, Uysal S, Karabulut E. Application of Kvaal et al.'s age estimation method to panoramic radiographs from Turkish individuals. Forensic Sci Int. 2012 Jun;219(1-3):141-6. https://doi.org/10.1016/j.forsciint.2011.12.012

8. Patil SK, Mohankumar KP, Donoghue M. Estimation of age by Kvaal's technique in sample Indian population to establish the need for local Indian-based formulae. J Forensic Dent Sci. 2014 Sep;6(3):166-70. https://doi.org/10.4103/0975-1475.137050

9. Kvaal SI, Kolltveit KM, Thomsen IO, Solheim T. Age estimation of adults from dental radiographs. Forensic Sci Int. 1995 Jul;74(3):175-85. https://doi.org/10.1016/0379-0738(95)01760-G

10. Azrak B, Victor A, Willershausen B, Pistorius A, Hörr C, Gleissner C. Usefulness of combining clinical and radiological dental findings for a more accurate noninvasive age estimation. J Forensic Sci. 2007 Jan;52(1):146-50. https://doi.org/10.1111/i.1556-4029.2006.00300.x

11. Balla SB, Galic I, P K, Vanin S, De Luca S, Cameriere R. Validation of third molar maturity index (I3M) for discrimination of juvenile/adult status in South Indian population. J Forensic Leg Med. 2017 Jul;49:2-7. https://doi.org/10.1016/i.jflm.2017.05.003

12. Marroquin Penaloza TY, Karkhanis S, Kvaal SI, Nurul F, Kanagasingam S, Franklin D, et al. Application of the Kvaal method for adult dental age estimation using Cone Beam Computed Tomography (CBCT). J Forensic Leg Med. 2016 Nov;44:178-82. https://doi.org/10.1016/i.jflm.2016.10.013

13. Panchbhai AS. Dental radiographic indicators, a key to age estimation. Dentomaxillofac Radiol. 2011 May;40(4):199-212. https://doi.org/10.1259/dmfr/19478385

14. Landa MI, Garamendi PM, Botella MC, Alemán I. Application of the method of Kvaal et al. to digital orthopantomograms. Int J Legal Med. 2009 Mar;123(2):123-8. https://doi.org/10.1007/s00414-008-0268-9 
15. Lanning SK, Best AM, Temple HJ, Richards PS, Carey A, McCauley LK. Accuracy and consistency of radiographic interpretation among clinical instructors using two viewing systems. J Dent Educ. 2006 Feb;70(2):149-59.

16. Cameriere R, Cunha E, Sassaroli E, Nuzzolese E, Ferrante L. Age estimation by pulp/tooth area ratio in canines: study of a Portuguese sample to test Cameriere's method. Forensic Sci Int. 2009 Dec;193(1-3):128.e1-6. https://doi.org/10.1016/i.forsciint.2009.09.011

17. Paewinsky E, Pfeiffer H, Brinkmann B. Quantification of secondary dentine formation from orthopantomograms-a contribution to forensic age estimation methods in adults. Int J Legal Med. 2005 Jan;119(1):27-30. https://doi.org/10.1007/s00414-004-0492-x

18. Bosmans N, Ann P, Aly M, Willems G. The application of Kvaal's dental age calculation technique on panoramic dental radiographs. Forensic Sci Int. 2005 Oct;153(2-3):208-12. https://doi.org/10.1016/i.forsciint.2004.08.017

19. Schmeling A, Geserick G, Reisinger W, Olze A. Age estimation. Forensic Sci Int. 2007 Jan;165(2-3):178-81.

https://doi.org/10.1016/j.forsciint.2006.05.016 